\title{
Structural and contact analysis of disc brake assembly during single stop braking event
}

\author{
Ali. Belhocine ${ }^{1, *}$, Abd. Rahim Abu Bakar², Mostefa Bouchetara ${ }^{1}$ \\ ${ }^{1}$ Faculty of Mechanical Engineering, University of Sciences and the Technology of Oran, El - MNAOUER, USTO ORAN, Algeria \\ ${ }^{2}$ Department of Automotive Engineering, Faculty of Mechanical Engineering, Universiti Teknologi Malaysia, Skudai, Malaysia
}

Email address:

al.belhocine@yahoo.fr (A. Belhocine), arahim@fkm.utm.my (Abd. R. A. Bakar), mbouchetara@hotmail.com (M. Bouchetara)

\section{To cite this article:}

Ali. Belhocine, Abd. Rahim Abu Bakar, Mostefa Bouchetara. Structural and Contact Analysis of Disc Brake Assembly during Single Stop Braking Event. American Journal of Mechanics and Applications. Vol. 2, No. 3, 2014, pp. 21-28. doi: 10.11648/j.ajma.20140203.12

\begin{abstract}
An automobile disc brake system is used to perform three basic functions, i.e. to reduce speed of a vehicle, to maintain its speed when travelling downhill and to completely stop the vehicle. During these braking events, the disc brake may suffer of structural and wear issues. It is quite sometimes that the disc brake components fail structurally and/or having severe wear on the pad. Thus, this paper aims to examine stress concentration, structural deformation and contact pressure of brake disc and pads during single braking stop event by employing commercial finite element software, ANSYS. The paper also highlights the effects of using a fixed caliper, different friction coefficients and different speeds of the disc on the stress concentration, structural deformation and contact pressure of brake disc and pads, respectively. Results from the investigation could provide a better explanation of the variation in contact pressure distribution and in turn squeal generation. Thus, this study provides effective reference for design and engineering application of brake disc and brake pad.
\end{abstract}

Keywords: Disc Brake, Von Mises Stress, Structural Deformation, Contact Pressure, Finite Element

\section{Introduction}

Passenger car disc brakes are safety-critical components whose performance depends strongly on the contact conditions at the pad to rotor interface. When the driver steps on the brake pedal, hydraulic fluid is pushed against the piston, which in turn forces the brake pads into contact with the rotor. The frictional forces at the sliding interfaces between the pads and the rotor retard the rotational movement of the rotor and the axle on which it is mounted [1]. The kinetic energy of the vehicle is transformed into heat that is mainly absorbed by the rotor and the brake pad.

During the engagement of clutch, pressure plate pushes the clutch disc towards the flywheel to bring it in contact with the flywheel and slipping occurs between the contact surfaces. At the beginning of engagement slipping occurs between the contact surfaces of the clutch system, as a result of this slipping heat is generated and the surface temperature increases gradually to higher values. In some cases temperature exceeds the maximum temperature limit of the material and eventually leads to premature failure [2].

Lee et al. [3] analyzed the effects of three load conditions of thermal loading, centrifugal force and contact pressure of diaphragm spring on pressure plate of a clutch system. The results show a significant effect of thermal loading and contact pressure that suggested an increase in the thickness of pressure plate to enhance the thermal capacity of pressure plate so that the thermal stresses may be reduced. Zagrodzki [4] studied the frictional heating in sliding systems and the effect of sliding speed on the stability of the system when the sliding speed exceeds the critical value. Finite element model was used to investigate the transient thermo-elastic process, spatial discretization and modal superposition is presented. Constant sliding speed was performed in this analysis. The transient solution includes both of homogenous part (corresponding to the initial condition) and non-homogenous part (represents the background process). The results show that the important parameters which contribute in the background process are the nominal process equivalent to uniform pressure distribution in isothermal case and the other is the pressure variation caused by geometric imperfection or by design features. Shahzamanian et al. [5] studied the transient and contact analysis of functionally graded (FG) brake disk. The coulomb contact friction is considered between the pad and the brake disc. It was found that the contact pressure and contact total stress increases with an increase in the contact stiffness factor.

The frictional heat generated on the interface of the disc 
and the pads can cause high temperature. Particularly, the temperature may exceed the critical value for a given material, which leads to undesirable effects, such as brake fade, local scoring, thermo elastic instability, premature wear, brake fluid vaporization, bearing failure, thermal cracks, and thermally excited vibration $[6,7]$. Gao and Lin [6] stated that there was considerable evidence to show that the contact temperature is an integral factor reflecting the specific power friction influence of combined effect of load, speed, friction coefficient, and the thermo physical and durability properties of the materials of a frictional couple. Lee and Yeo [7] reported that uneven distribution of temperature at the surfaces of the disc and friction pads brings about thermal distortion, which is known as coning and found to be the main cause of judder and disc thickness variation (DTV). Abu Bakar et al [8] in their recent work found that temperature could also affect vibration level in a disc brake assembly. Valvano and Lee [9] simulated thermal analysis on a disc brake with a combination of computer based thermal model and finite element based techniques to provide a reliable method to calculate the temperature rise, thermal stress and distortion under a given brake schedule. Wolejsza et al [10] performed analysis on the thermo-mechanical behavior of airplane carbon composite brakes using MSC/Marc finite element software which allows accurate simulation of the transient heat transfer phenomenon coupled to disc deformations caused by frictional sliding contact.

There are three types of mechanical stresses subjected by the disc brake. The first one is the traction force created by the centrifugal effect due to the rotational of the disc brake when the wheel is rotating and no braking force is applied to the disc. During braking operation, there are another two additional forces experienced by the disc brake. Firstly, compression force is created as the result of the force exerted by the brake pad pressing perpendicular onto the surface of the disc to slow it down. Secondly, the braking action due to the rubbing of the brake pad against the surface of the disc brake is translated into frictional or traction force on the disc surface which acts in the opposite direction of the disc rotation.

A disc brake of floating caliper design typically consists of pads, caliper, carrier, rotor (disc), piston, and guide pins. One of the major requirements of the caliper is to press the pads against the rotor and should ideally achieve as uniform interface pressure as possible. A uniform pressure between the pads and rotor leads to uniform pad wear and brake temperature, and more even friction coefficients [11]. Unevenness of the pressure distribution could cause uneven wear and shorter life of pads. It has also speculated that they may promote disc brake squeal. The interface pressure distributions have been investigated by a number of people. Tirovic and Day [12] studied the influence of component geometry, material properties and contact characteristics on the interface pressure distribution. They used a simple and non validated, three-dimensional model of the disc brake. Tamari et al. [13] presented a method of predicting disc brake pad contact pressure for certain operating condition by means of experimental and numerical method. They developed a quite detailed model and validated the model by fitting the numerical deformations of the disc brake components with experimental results. Hohmann et al. [14] also presented a method of contact analysis for the drum and disc brakes of simple three-dimensional models using ADINA software package. They showed a sticking and shifting contact area in their results. Like [12], validation of their model was not made. The interface pressure distribution of drum brakes was also studied by Huang and Shyr [15] by the boundary element method. Day et al. [16] used final element method (FEM) to predict the pressure distribution at the interface of a drum brake and extended their work [17] by carrying out combined thermal and mechanical analysis for the calculation of pressure distribution by considering lining wear and thermal distortions. In their extended work, separate finite element mesh was considered for the structural and thermal analysis.

Ripin [18] developed a simple, validated three-dimensional finite element model of the pad, and applied rather simple piston and finger force onto the back plate interface in his analysis. He studied the contact pressure distribution at the disc/pad interface, where gap elements were used to represent contact effect.

In this paper, structural analysis is performed on a simple finite element (FE) model of a real disc brake assembly to obtain the contact pressure distributions on the friction pads and the Von Mises Stress in disc interface by utilizing the ANSYS 11.0 FE software. Sensitivity study on rotation of the disc, load pattern and coefficient of friction is also performed.

\section{Finite Element Model and Simulation}

Table 1. Mechanical properties of the disc and pad

\begin{tabular}{lll}
\hline Properties & Disc & Pad \\
\hline Young modulus $E(\mathrm{GPa})$ & 138 & 1 \\
Poisson's ratio $v$ & 0.3 & 0.25 \\
Density $\rho\left(\mathrm{kg} / \mathrm{m}^{3}\right)$ & 7250 & 1400 \\
Coefficient of friction $\mu$ & 0.2 & 0.2 \\
\hline
\end{tabular}

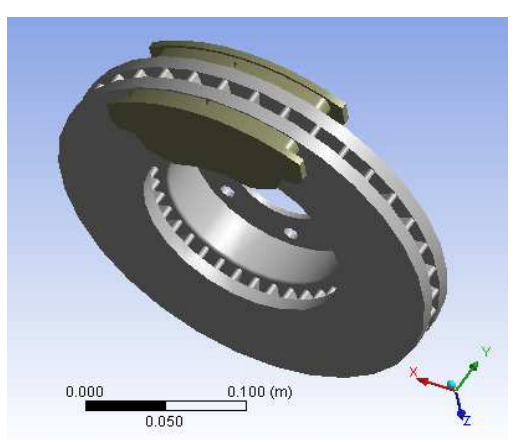

Figure 1. CAD model of the disc and pads.

In this work, a three dimensional $\mathrm{CAD}$ and $\mathrm{FE}$ model consists of a ventilated disc and two pads with single slot in the middle as illustrated in Fig.1 and Fig. 2, respectively. The selected material of the disc is Gray cast iron FG 15 with high 
Carbon content and the brake pad has an isotropic elastic behavior whose mechanical characteristics of the two parts are presented in Table 1. The materials of the disc and the pads are homogeneous and their properties are invariable with the temperature.

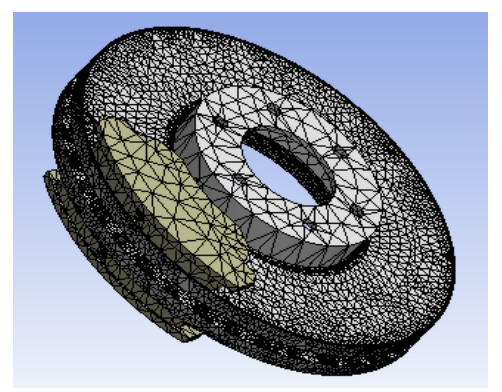

Figure 2. FE model of the disc and pads.

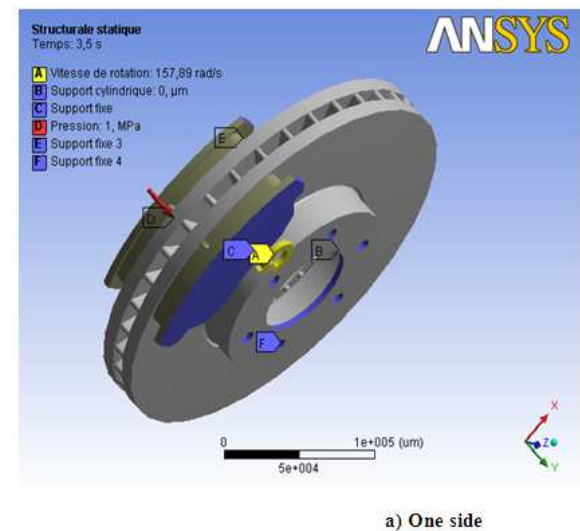

A commercial FE software, namely ANSYS 11 (3D) is fully utilised to simulate structural deformation and contact pressure distributions of the disc brake during single braking stop application. Boundary conditions are imposed on the models (disc-pad) as shown in Fig. 3(a) for applied pressure on one side of the pad and Fig.3 (b) for applied pressure on both sides of the pad. The disc is rigidly constrained at the bolt holes in all directions except in its rotational direction. Meanwhile, the pad is fixed at the abutment in all degrees of freedom except in the normal direction to allow the pads move up and down and in contact with the disc surface. In this study, it is assumed that $60 \%$ of the braking forces are supported by the front brakes (two rotors) [19]. By using vehicle data as given in Table 2 and Eqs (1)-(3), braking force on the disc, rotational speed and brake pressure on the pad can be calculated, respectively.

Figure 3. Boundary conditions and loading imposed on the disc-pads.

Table 2. Vehicle data

\begin{tabular}{ll}
\hline Item & Valueva \\
\hline Mass of the vehicle, $\mathrm{M}[\mathrm{kg}]$ & 1385 \\
Initial velocity $-v_{0} \quad[\mathrm{~m} / \mathrm{s}]$ & 60 \\
Time to stop $t_{\text {stop }} \mathrm{s}$ & 45 \\
Effective rotor radius $-R_{\text {rotor }}[\mathrm{mm}]$ & 101 \\
Radius of the wheel $-R_{\text {tire }}[\mathrm{mm}]$ & 380 \\
The coefficient of friction disc/pads $\mu$ & 0.2 \\
Surface area of the pad $A_{c}\left[\mathrm{~mm}^{2}\right]$ & 5246 \\
\hline
\end{tabular}

$$
F_{\text {disc }}=\frac{(30 \%) \cdot \frac{1}{2} M v_{0}^{2}}{2 \cdot \frac{R_{\text {rotor }}}{R_{\text {tire }}}\left(v_{0} \cdot t_{\text {stop }}-\frac{1}{2}\left\{\frac{v_{0}}{t_{\text {stop }}}\right\} t_{\text {stop }}^{2}\right)}=1047.36[\mathrm{~N}]
$$

The rotational speed of the disc is calculated as follows:

$$
\omega=\frac{v_{0}}{R_{\text {tire }}}=157.89 \mathrm{rad} / \mathrm{s}
$$

The external pressure between the disc and the pads is calculated by the force applied to the disc; for a flat track, the hydraulic pressure is, as referred to [20]:

$$
P=\frac{F_{\text {disc }}}{A_{c} \cdot \mu}=1[\mathrm{MPa}]
$$

Where $A_{c}$ is the area surface of the pad in contact with the disc and $\mu$ the coefficient of friction.

\section{Results and Discussion}

\subsection{Von Mises Stress distribution}

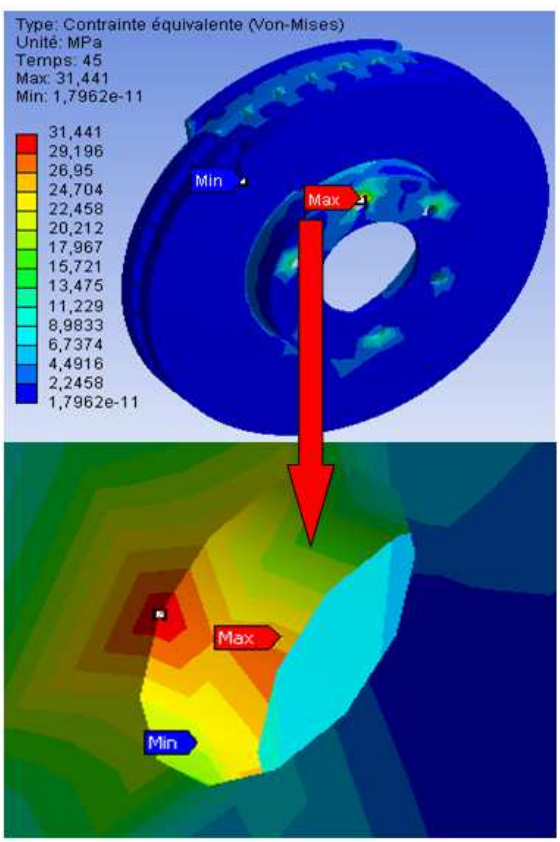

Figure 4. Stress concentration at the bolt holes. 
Fig.4. shows distributions of the equivalent Von Mises stress over braking period and it is shown that the highest stress occurs at the bolt holes at the time $\mathrm{t}=0.25 \mathrm{~s}$. This is due to the disc having experience in torsion and shear modes. This high stress concentration can cause a rupture to the bolt holes.

\subsection{Contact Pressure Distribution}

Fig.5 illustrates contact pressure distributions of the inner pad at different braking times. It shows that the contact pressure increases gradually and reaches its maximum value of Pmax $=1.8 \mathrm{MPa}$ at the end of braking period. It is believed that the rise in pressure on the contact surface can also cause a rise in the temperature of the disc and wear of the pads. At the leading side and inner radius of the pad, contact pressure is seen to be higher compared to the other regions. This is due to this area is mostly in contact with the disc surface. Fig 6. shows the evolution of contact pressures along angular positions of the pad. The maximum value of the contact pressure is located at the leading edge and at the level of the lower edge of the pad. Contact pressure distributions of the outer pad are depicted in Fig. 7. It shows that the maximum contact pressure is predicted in the middle of the pad with the value of 1.3 MPa. This is much lower than that obtained on the inner pad.

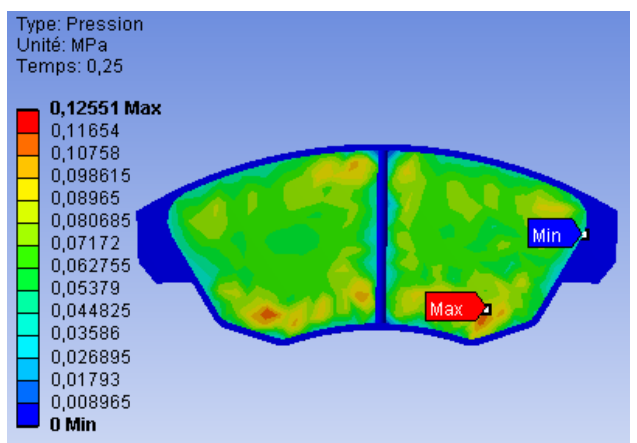

a) at time $\mathrm{t}=0.25 \mathrm{~s}$

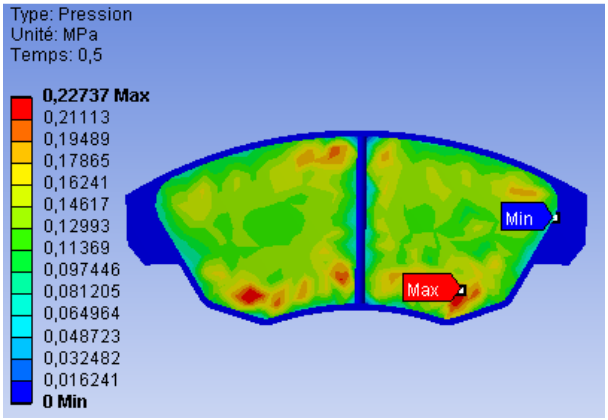

b) at time $\mathrm{t}=0.5 \mathrm{~s}$

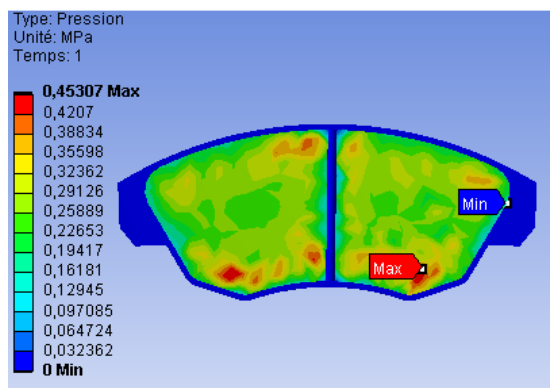

c) at time $\mathrm{t}=1 \mathrm{~s}$

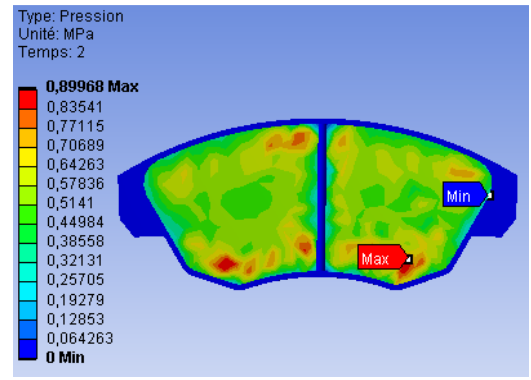

(d) at time $\mathrm{t}=2 \mathrm{~s}$

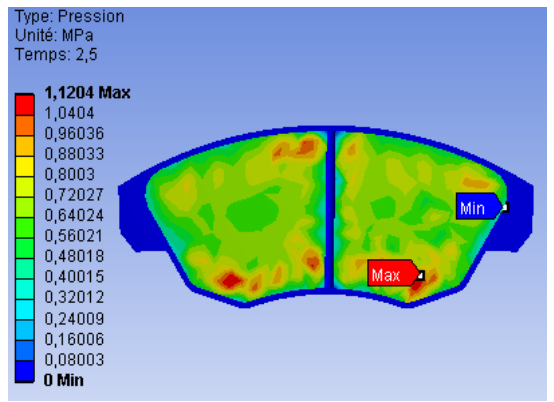

(e) at time $\mathrm{t}=2.5 \mathrm{~s}$

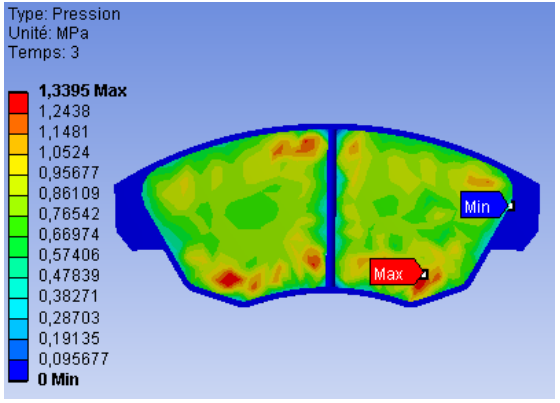

(f) at time $\mathrm{t}=3 \mathrm{~s}$

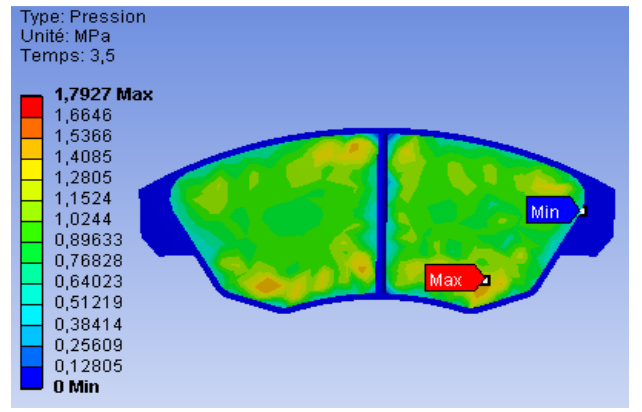

(g) at time $\mathrm{t}=3.5 \mathrm{~s}$ 


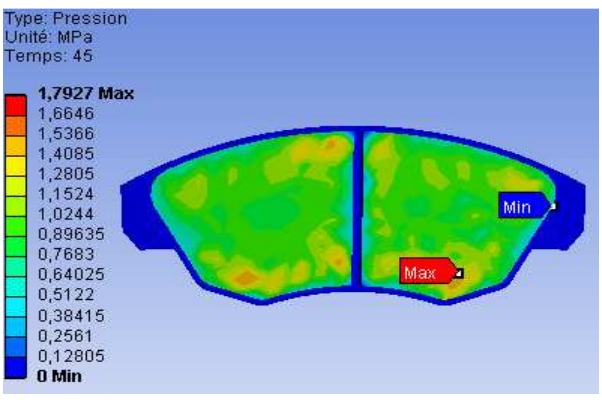

(h) at time $\mathrm{t}=45 \mathrm{~s}$

Figure 5. Contact pressure distribution on the inner pad.

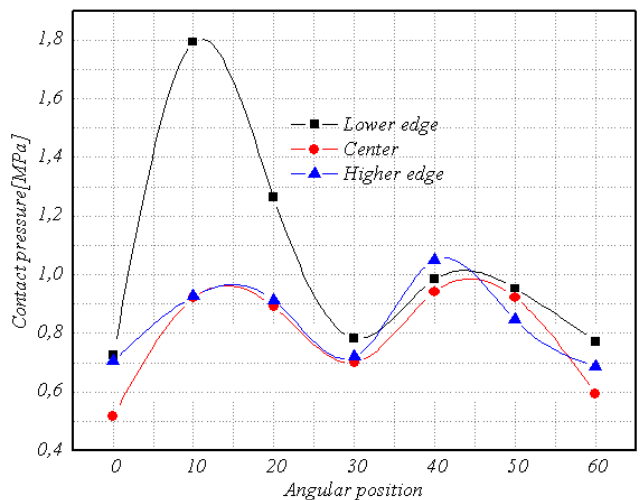

Figure 6. Variation of contact pressures according to the angular position in the inner pad.

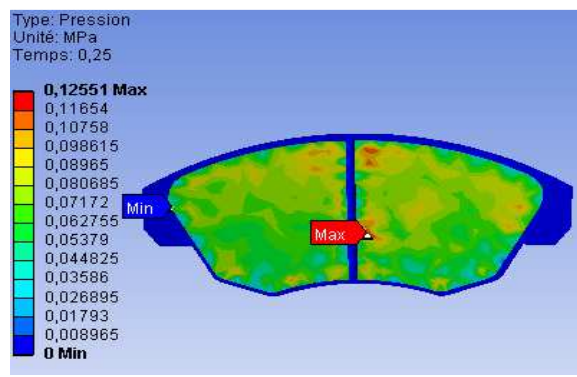

(a) at time $\mathrm{t}=0.25 \mathrm{~s}$

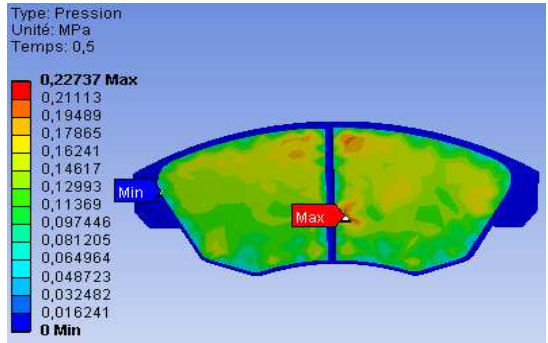

b) at time $\mathrm{t}=0.5 \mathrm{~s}$

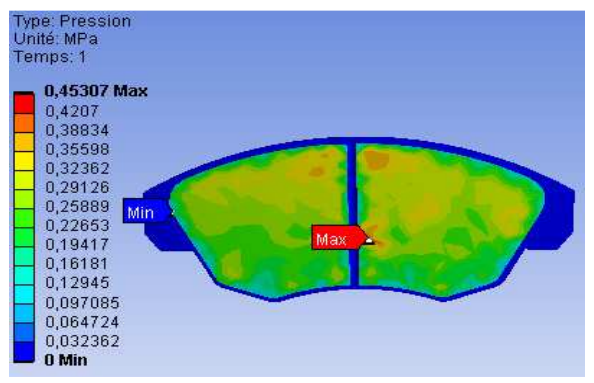

c) at time $\mathrm{t}=1 \mathrm{~s}$

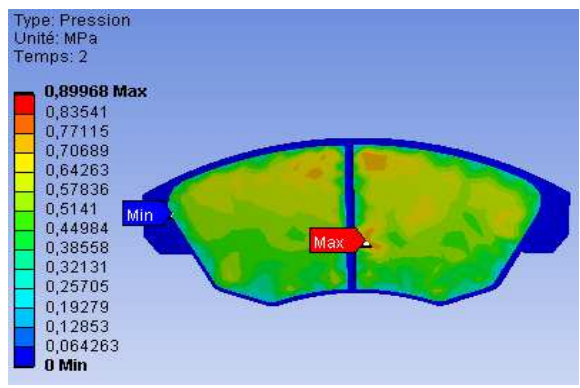

d) at time $\mathrm{t}=2 \mathrm{~s}$

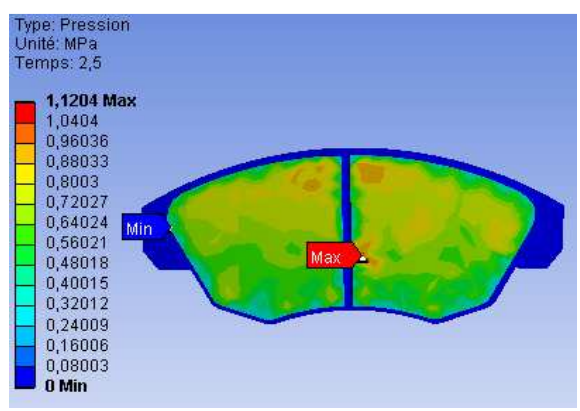

e) at time $\mathrm{t}=2.5 \mathrm{~s}$

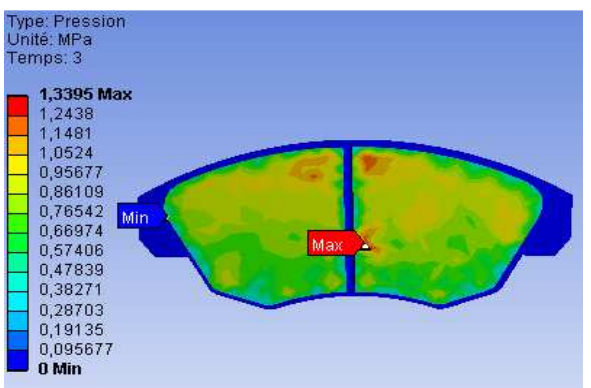

(f) at time $t=3 \mathrm{~s}$

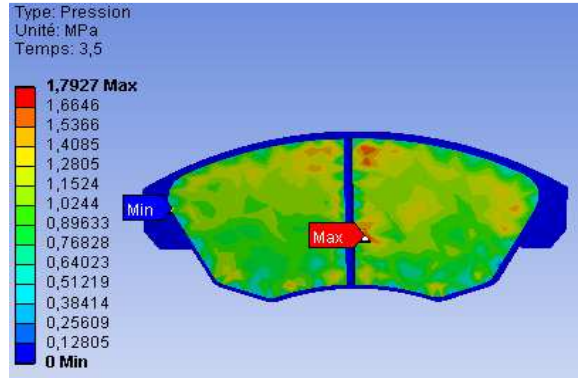

(g) at time $\mathrm{t}=3.5 \mathrm{~s}$ 


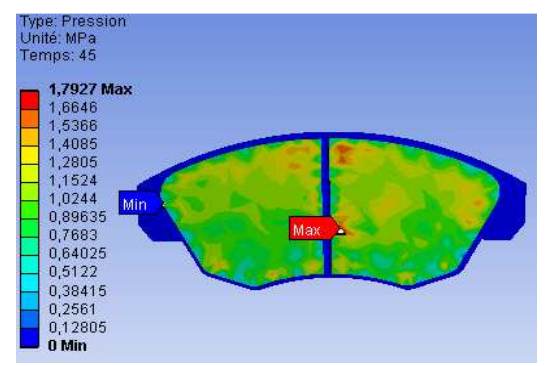

(h) at time $\mathrm{t}=45 \mathrm{~s}$

Figure 7. Contact pressure distribution on the outer pad.
For a comparative study, the effect of a fixed caliper (disc with double pressure) is also simulated where it maintains the same boundary conditions used in the case of a single-piston caliper. Fig.8.shows the levels of equivalent Von Mises stresses in a section of a disc brake at the end of braking period. Unlike the case of the disc with a single-piston caliper, it is noted that the highest stress appears at the outer side of the fins with the value of 8.3 MPa. This is lower than the stress predicted at the bolt holes with the value of $31.4 \mathrm{MPa}$ for single-piston caliper. It is also found that the stress is well distributed to the disc interface compared with stress predicted in Fig. 5.

\subsection{Effect of a Fixed Caliper}
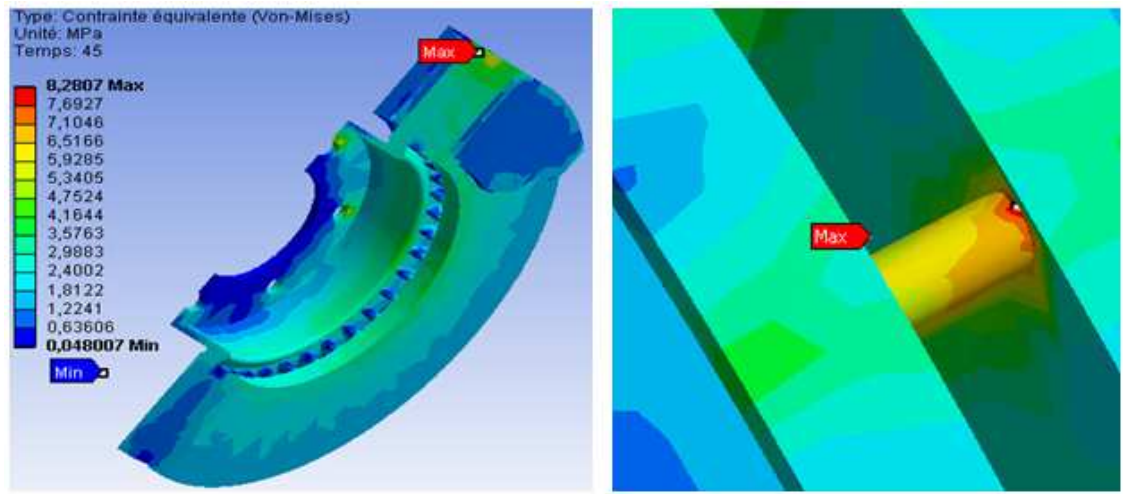

Figure 8. Von Mises stresses.

\subsection{Effect of Friction Coefficient}

It is interesting to see deformation behavior of the disc and the pads with respect to variation of friction coefficient from 0.25 to 0.35 . Fig.9. shows the different configurations of the total deformation of the model in the final stage of braking. It is clearly seen that the total deformation is slightly decreased with the increase of friction coefficient. Indeed, the high mechanical advantage of hydraulic and mechanical disc brakes allows a small lever input force at the handlebar to be converted into a large clamp force at the wheel. This large clamp force pinches the rotor with friction material pads and generates brake power. The higher the coefficient of friction for the pad, the more brake power will be generated coefficient of friction can vary depending on the type of material used for the brake rotor. If the value of the coefficient of friction is increased, the disc is slowed down by friction forces which are opposed to its movement, and the maximum deformation that it undergoes is less significant.

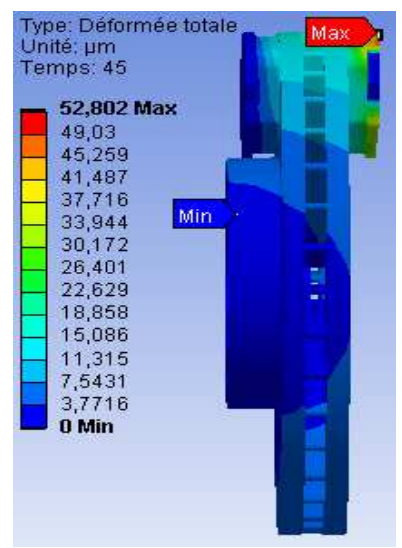

(a) $\mu=0.25$

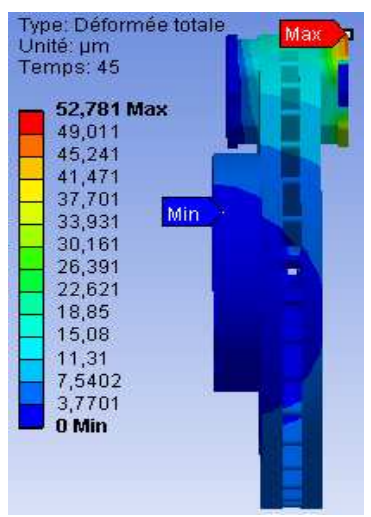

(b) $\mu=0.30$ 


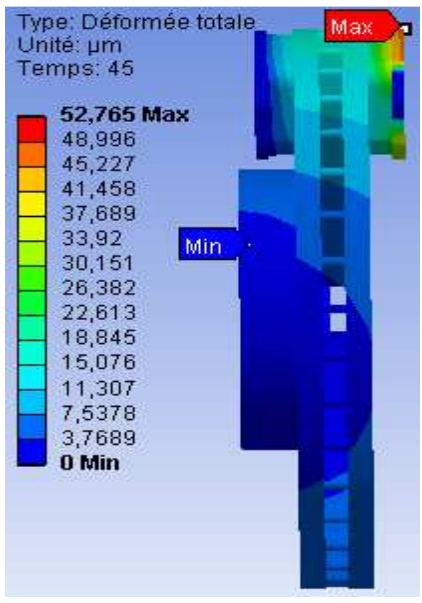

(c) $\mu=0.35$

Figure 9. Total deformation at the end of braking period.

\subsection{Effect of Disc Speed}

Fig.10.shows prediction of contact pressure distributions at three different speeds of the disc. It is found that contact pressure distribution is almost identical in all three cases and its value increases with the increase of the angular velocity of the disc. This was also confirmed by Abu Bakar et al. [21]. It is believed that this increase can create the wear of the pads as they can leave deposits on the disc, giving rise to what is called "the third body." It is noted that the maximum contact pressure is produced on the pad at the leading edge.

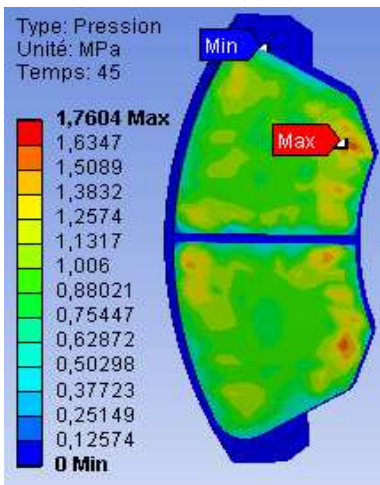

(a) $\omega=60 \mathrm{rad} / \mathrm{s}$

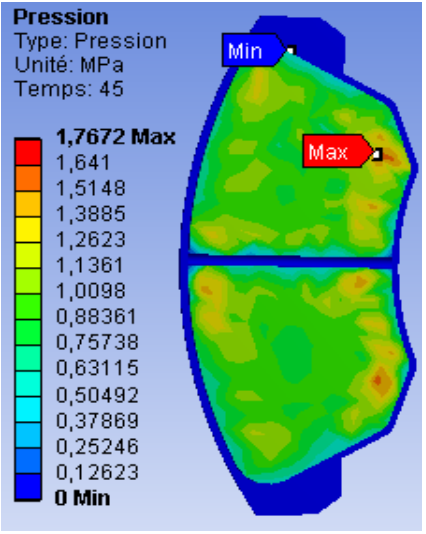

(b) $\omega=90 \mathrm{rad} / \mathrm{s}$

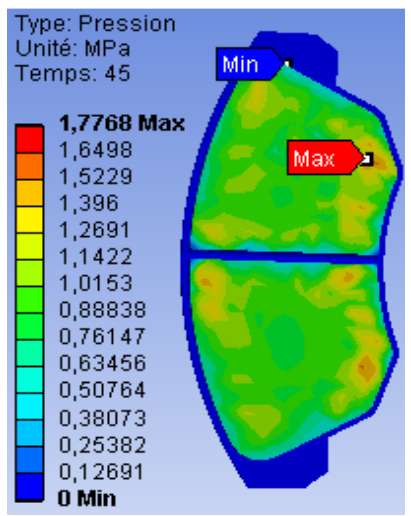

(c) $\omega=120 \mathrm{rad} / \mathrm{s}$

Figure 10. Contact pressure distributions.

\section{Conclusion}

This paper presents structural and contact analysis of a reduced brake model without considering thermal effects. The analysis is performed using commercial FE software package, ANSYS where the FE model only consists of a disc and two pads. All the values obtained from the analysis are less than their allowable values. Hence the brake disk design is safe based on the strength and rigidity criteria.

From the single stop braking simulation it is found that:

- the bolt holes and outer side of the fins could first damage due to high stress concentration for single and double piston case, respectively

- $\quad$ contact pressure is predicted higher at the leading side compared to the trailing side and its value slightly increases with the increase of disc rotation speeds

- there is no significant change in disc-pad deformation with respect to the variation of friction coefficient

It is interesting to see how these prediction results match to the experimental data. This is the subject of the authors having the experimental means and works of future extension.

Regarding the outlook, there are two recommendations for the work related to disc brake that can be done to further understand the effects of thermo-mechanical contact between the disc and pads, the recommendations are as follows:

- Tribological and vibratory study of the contact disc - pads;

- Study of dry contact sliding under the macroscopic aspect (macroscopic state of the surfaces of the disc and pads).

\section{References}

[1] A.Söderberg, S.Andersson. Simulation of wear and contact pressure distribution at the pad-to-rotor interface in a disc brake using general purpose finite element analysis software, Wear, vol.267,pp.2243-2251,2009. 
[2] O.I. Abdullah, J. Schlattmann, A.M. Al-Shabibi, "Stresses and Deformations Analysis of a Dry Friction Clutch System," Tribology in Industry, vol. 35, no. 2, pp. 155-162, 2013.

[3] C.Y.Lee, S.Chung, Y.S.Chai, "Finite Element Analysis of an Automobile Clutch System," Key Engineering Materials, vol. 353-358, pp. 2707-2711, September 2007.

[4] P.Zagrodzki, "Thermoelastic Instability in Friction Clutches and Brakes-Transient Modal Analysis Revealing Mechanisms of Excitation of Unstable Modes," International Journal of Solids and Structures, vol. 46, pp. 2463-2476, 2009.

[5] M.M. Shahzamanian, B.B. Sahari, M. Bayat, Z.N. Ismarrubie and F. Mustapha, "Transient and Thermal Contact Analysis for the Elastic Behavior of Functionally Graded Brake Disks Due to Mechanical and Thermal Loads," Journal of Materials \& Design,vol.31,no.10,pp. 4655-4665,2010.

[6] C.H. Gao and X.Z. Lin. Transient temperature field analysis of a brake in a non-axisymmetric threedimensional model, $J$. Materials Processing Technology, 129 (2002) 513-517.

[7] S. Lee and T. Yeo. Temperature and coning analysis of brake rotor using an axisymmetric finite element technique, Proc. 4th Korea-Russia Int. Symp. On Science \& Technology, 3(2000) 17-22.

[8] A.R. Abu Bakar, H. Ouyang, and L. Li. A combined analysis of heat conduction, contact pressure and transient vibration of a disc brake, Int. J. Vehicle Design, 51(1/2), (2009) 190-206.

[9] T. Valvano and K. Lee. An analytical method to predict thermal distortion of a brake rotor, SAE Technical Paper, (2000) 2000-01-0445.

[10] Z. Wolejsza, A. Dacko, T. Zawistowki, and J. Osinski. Thermo-Mechanical Analysis of Airplane Carbon-Carbon Composite Brakes Using MSC. Marc, Warsaw University of Technology, (2001), Paper 2001-58.

[11] Limpert, R. Brake design and safety (Second Edition). Society of Automotive Engineers, 1999.
[12] Tirovic, M. and Day, A. J. "Disc brake interface pressure distributions". Proc. I MechE, Part D, vol.205,pp.137-146, 1991.

[13] Tamari, J., Doi, K. and Tamasho, T. Prediction of contact pressure of disc brake pad. Society of Automotive Engineering, Review, vol.21, pp.133-141, 2000.

[14] Hohmann, C., Schiffner, K., Oerter, K. and Reese, H. "Contact analysis for drum brakes and disk brakes using ADINA". Computers and Structures, vol.72, pp.185-198, 1999.

[15] Y.M. Huang, and J.S. Shyr, "On pressure distribution of drum brakes ”. ASME J. Mech. Des., vol.124, pp.115-120, 2002.

[16] A. J.Day, P. R. J.Harding, and T. P. Newcomb, A finite element approach to drum brake analysis. "Proc. Instn Mech. Engrs, vol.193, pp.401-406, 1979.

[17] A. J.Day, P. R. J.Harding, and T. P. Newcomb, "Combined thermal and mechanical analysis of drum brakes. Proc. IMechE, Part D: Transport Engineering, vol.198(D), pp.287-294, 1984.

[18] Ripin, Z. B. M. Analysis of Disc Brake Squeal Using the Finite Element Method. PhD Thesis, University of Leeds, 1995.

[19] T.T.Mackin, S.C.Noe, K.J.Ball, B.C.Bedell, D.P.Bim-Merle, M.C.Bingaman, D.M.Bomleny, G.J.Chemlir, D.B.Clayton, and H.A.Evans, Thermal cracking in disc brakes. Eng. Failure Analysis, vol.9, pp.63-76, 2002.

[20] G.Oder, M.Reibenschuh, T.Lerher, M.Šraml, B.Šamec, I.Potrč. "Thermal and stress analysis of brake discs in railway vehicules"Advanced Engineering 3(2009)1, ISSN 1846-5900

[21] A. R.Abu Bakar, H.Ouyang and Q.Cao " Interface Pressure Distribution through Structural Modifications" SAE Technical Paper, 2003-01-3332 